\title{
Conclusiones del Congreso Internacional "El Espíritu de las Ciudades de Europa: Cáceres"
}

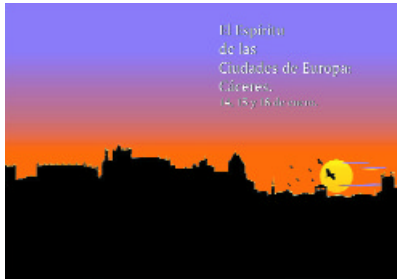

Cartel del Congreso
Con la intención de abordar aspectos relacionados con el urbanismo y la calidad de vida en Cáceres -y conformando una importante "puerta abierta" de cara a la candidatura de la ciudad a Capital Cultural Europea en 2016- se organizó el Congreso Internacional "El espíritu de las ciudades de Europa: Cáceres", del 14 al 16 de enero de 2004. A continuación se exponen algunas de las conclusiones del congreso, que fue promovido por la Fundación Academia Europea de Yuste, con la colaboración de la Consejería de Fomento de la Junta de Extremadura y el Ayuntamiento de Cáceres, entre otras instituciones.

$>$ La velocidad a la que se suceden los procesos urbanos y territoriales hoy obligan a plantear planificaciones flexibles que analicen, en un proceso continuo y dinámico, tanto las transformaciones como los límites o capacidad de canje que están dispuestas a soportar las ciudades. Los cambios de uso en los centros históricos deben controlarse exhaustivamente para evitar que el espacio de escala humana y referencia histórica se trivialice, perdiendo el sentido y el espíritu propios de cada ciudad, haciendo que todas se parezcan. La idea de proyecto, la idea de ciudad, la personalidad de la población urbana, la singularidad de los centros históricos, en definitiva, deben preservarse como valores propios, únicos y perceptibles, huyendo de la falsa homogeneidad.

> La calidad de vida en la ciudad está relacionada con la sostenibilidad de todos sus procesos, consumos, funcionamiento, emisiones y residuos. Calidad y sostenibilidad, que no son objetivos que puedan conseguirse aisladamente en ciudades concretas del mundo, son conceptos que exigen una visión global y una alta dosis de solidaridad regional, nacional e internacional. La calidad de vida es un estado que sólo puede conseguirse con un cambio de comportamiento social que modifique nuestros hábitos de consumo y nuestra escalada de crecimiento exponencial en los parámetros que suponen un crecimiento de nuestra huella ecológica.

$>$ El concepto de ciudad ideal no existe más que en el terreno de las ideas, independientemente de todo contexto situacional específico. Sin embargo, es la utopía, es decir, el intento arriesgado y hoy en descrédito de franquear la frontera de la realidad, la que debe suscitar la reflexión y estimular el cambio en el mundo real, originando las condiciones propicias desde las que el medio ambiente urbano futuro podrá continuar beneficiándose de esta función vital. En este sentido, como recordaba Lewis Mumford (1895) "un mapa del mundo que no incluya la utopía no merece siquiera una mirada".
$>$ No pronunciarás el nombre ciudad en vano. Es inaceptable confundir los problemas y las soluciones de la ciudad con los de otras realidades: áreas metropolitanas, regiones urbanas 0 galaxias urbanas. En una democracia sin objetivos, es decir, con libertad en el campo económico, la planificación es el instrumento indispensable para superar las contradicciones territoriales.

> Las infraestructuras de abastecimiento y saneamiento serían tanto más contribuidoras a la calidad de vida y a la sostenibilidad de las ciudades cuanto menos se hicieran presentes en su paisaje urbano, confundiéndose con su fisonomía habitual.

$>$ Hay que gestionar una política de demandas que no haga peligrar el equilibrio con el recurso; para ello: cultura, ahorro y reutilización.

> Cáceres se encuentra obligada a especializar su modelo urbano funcional. El reto es patrimonial, turístico-cultural y ambiental, obligando a la integración de instrumentos y estrategias públicas y privadas en su gestión.

$>$ Como consecuencia de la encuesta realizada, previa a este congreso, el grado altamente satisfactorio y positivo manifestado por los cacereños en los factores relacionados con el atractivo de la ciudad, con el impacto visual agradable que les produce, con el nivel de activación y de seguridad que les evoca, facilita el proceso de identidad en su ciudad y un alto grado de autoestima. Aún cuando la experiencia emocional de mayores y jóvenes sea significativamente distinta, se pone de manifiesto una opinión bastante homogénea, sin que se evidencien diferencias generacionales en la valorización global entre la zona antigua y moderna.

$>$ Cáceres debe definirse en la necesaria convergencia de compromisos institucionales públicos, privados, empresariales y ciudadanos, como cauce obligado en la consecución de su futuro.

Teófilo González Porras

Director Técnico del Congreso 